\title{
Patrimônio cultural naval e proposta de roteiros turísticos para as embarcações tototós pelo estuário do Rio Sergipe
}

Naval Cultural Heritage and Proposal for Tours in the Tototós Boats by the Estuary of the Rio Sergipe

Patrimonio Naval e Itinerarios Turísticos Propuestos para los Barcos Tototós por el Estuario del Río Sergipe

http://dx.doi.org/10.18472/cvt.16n2.2016.1152

Gabriela Nicolau dos Santos 〈gabrielanicolau.80@gmail.com >

Rosa dos Ventos Consultoria e Pesquisa, Brasil.

Ivan Rêgo Aragão <ivan_culturaeturismo@hotmail.com >

Rosa dos Ventos Consultoria e Pesquisa, Brasil.

Acacia Maria Barros Souza 〈acaciaravel3o@hotmail.com >

Rosa dos Ventos Consultoria e Pesquisa, Brasil.

CRONOLOGIA DO PROCESSO EDITORIAL

Recebimento do Artigo: 30-out-2014

Aceite: 22-jun-2016

FORMATO PARA CITAÇÃO DESTE ARTIGO

DOS SANTOS, G. N.; ARAGÃO, I. R.; SOUZA, A. M. B. Patrimônio Cultural Naval e Proposta de Roteiros Turísticos para as Embarcações Tototós pelo estuário do Rio Sergipe. Caderno Virtual de Turismo. Rio de Janeiro, v. 16, n. 2, p. 93-110, ago. 2016.

$$
\text { REALIZAÇÃO }
$$

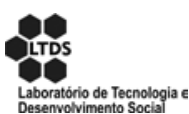

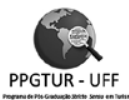

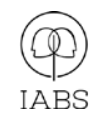

APOIO INSTITUCIONAL

COPPE

UFR]

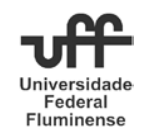

EDIÇÃO

PATROCÍNIO

IRTOR 


\section{RESUMO}

Desde o final da década de 1940, as embarcações do tipo tototó cumprem a função de transportar passageiros entre as margens na foz do baixo Rio Sergipe. Em 2011, receberam o título de Patrimônio Cultural e Imemorial do Estado de Sergipe pelo Decreto-Lei n. 7.320. A partir da pesquisa bibliográfica, trabalho de campo e adoção da metodologia do Inventário Nacional de Referências Culturais (INRC/Iphan), o presente estudo propõe roteiros turísticos pela foz do Rio Sergipe proporcionando outros itinerários para essas embarcações. Uma das soluções verificadas em campo se pautou na elaboração de roteiros dentro do segmento do Turismo de Base Comunitária, onde os canoeiros seriam protagonistas desses circuitos gerando um impacto positivo para a cadeia produtiva do turismo em Barra dos Coqueiros. Essa ação poderia tornar-se uma ferramenta de educação, conhecimento e preservação dos bens culturais e ambientais que se vinculam ao espaço, sendo o ofício do canoeiro e os demais saberes da localidade, valorizados. Os roteiros seriam geridos pelos próprios barqueiros ou pessoas da comunidade interessadas em desenvolver o turismo sob essa ótica.

Palavras-chave: Patrimônio Cultural Naval. Turismo de Base Comunitária. Embarcações Tototós.

\section{ABSTRACT}

Since the end of the decade of 1940, the tototo boats comply with the function of transporting passengers between the shore at the mouth of bass River. In 2011 received the title of Cultural Heritage and Immemorial State of Sergipe by Decree-Law N. 7,320. From the bibliographical research, field work and adoption of the methodology of the National Inventory of Cultural References (INRC/IPHAN), this study proposed tours touristics of the rio Sergipe providing other itineraries for these boats. One of the solutions verified on-site if took on roadmapping within the community based tourism segment, where the boatmen would be protagonists of these circuits generating a positive impact to the production chain of tourism in Barra dos Coqueiros. This proposal should consist of in addition to the locally based tourism, other segments such as the educational, scientific, cultural and eco-tourism. This action could become a tool of education, knowledge and the preservation of cultural and environmental assets that link to space, being the trade of and knowledge of canoeiro locality, valued. The scripts would be managed by boatman or people in the community interested in developing the tourism in this optics.

Keywords: Naval Cultural Heritage. Community-Based Tourism. Tototó Boats.

\section{RESUMEN}

Desde finales de la década de 1940, los barcos tipo tototó cumplan con la función de transporte de pasajeros entre la costa en la desembocadura del bajo río Sergipe. En 2011, recibió el título de Patrimonio Cultural y Inmemorial de la Província por Decreto Ley N. 7320. Desde la investigación bibliográfica, trabajo de campo y adopción de la metodología del inventario nacional de referencias culturales (INRC/IPHAN), este estudio propone excursiones por la desembocadura del río Sergipe proporcionando otros circuitos para estos barcos. Una de las soluciones verificadas in situ fu la construcción de intinerarios dentro del segmento de turismo de base en comunidad, donde los barqueros serían protagonistas de estos circuitos generando un impacto positivo a la cadena de producción de turismo en Barra dos Coqueiros. Esta acción podría convertirse en una herramienta de educación, conocimiento y la preservación del patrimonio cultural y ambiental que vinculan al espacio, siendo el oficio de canoero y otros conocimientos de la localidade, valorados. Los intinerarios estarían dirigidos por los barqueiros o personas de la comunidad interesada en el desarrollo del turismo en esta óptica.

Palabras clave: Patrimonio naval. Turismo de Base Comunitaria. Tototós. 


\section{INTRODUÇÃO}

O presente artigo faz parte dos estudos ${ }^{1}$ solicitados pelo Iphan ${ }^{2}$ a Fundação Alphaville como medida compensatória pelos impactos aos sítios arqueológicos Alphaville I e II, localizados no município de Barra dos Coqueiros, Sergipe. A partir de uma série de relatórios, entre eles um Plano de Salvaguarda, despontou a elaboração dos quatro roteiros turísticos em que seriam utilizadas as embarcações tototós como transporte de estudantes e turistas.

Segundo estudos realizados in loco, verificou-se que as tototós são embarcações simples, construídas em madeira, com cabine para seus passageiros, que viajam sentados, cuja principal função é o transporte destes. Possuem cerca de três metros de largura e 15 metros de comprimento e são batizadas com esse nome graças ao som característico emitido por seu motor de popa. Muito tradicionais no uso, formato e estética, são sempre avistadas na travessia de pessoas que cruzam as margens das cidades de Aracaju e Barra dos Coqueiros, fazendo parte da paisagem, memória e identidade cultural da população do estuário do Rio Sergipe. ${ }^{3}$

A pesquisa faz parte das obrigações do Termo de Compromisso supracitado. Foi executada por meio do estudo bibliográfico, para o aporte teórico-conceitual sobre patrimônio cultural e patrimônio cultural naval, turismo de base comunitária; e pesquisa de campo para reconhecimento da área estudada com visitas técnicas aos pontos descritos no roteiro turístico.

A fase de identificação do Bem seguiu a proposta do Inventário Nacional de Referências Culturais INRC (BRASIL, 2000), como forma de entender os sentidos e significados que o patrimônio cultural naval possui para a população do entorno. Além disso, a equipe elaborou material fotográfico relativo às tototós e cartográfico por meio das imagens do google satélite adquiridas através da ferramenta open layers plugin do QGIS. ${ }^{4}$

A proposta de Turismo de Base Comunitária surgiu como uma solução percebida pela equipe para a realidade dos canoeiros. Estes encontram-se desvalorizados, esquecidos e sem reconhecimento não somente pela comunidade, como pelo poder público. Mesmo o ofício sendo patrimonializado em nível estadual, ações de continuidade do ofício foram previstas pelo Iphan por meio do Plano de Salvaguarda.

No entanto, a realidade dos citados barqueiros permanece necessitando de melhorias, tanto salarial como de benefícios previdenciários, além de maior reconhecimento e divulgação do trabalho naval dos totozeiros (Figura 1). Nesse contexto, a proposta de implantar o turismo de base comunitária poderia ser uma solução para não somente dar novos usos às embarcações, como gerar renda por outra atividade e trazer maior visibilidade à categoria.

A execução de roteiros turísticos proporcionaria protagonismo e gestão realizados pelos totozeiros de circuitos que integrariam a beleza cênica do estuário do Rio Sergipe com o seu meio ambiente natural, o patrimônio histórico-cultural de Aracaju que se encontra à beira do Rio Sergipe, os atrativos e equipamentos turísticos. Roteiros estes, já realizados por alguns canoeiros como meio de melhoria de renda, porém, elaborados de forma incipiente e sem buscar uma integração e diálogo com a cadeia produtiva do turismo de Barra dos Coqueiros, como bares, restaurantes, pousadas, hotéis e ONGs.

\footnotetext{
1 A Fundação Alphaville contratou a Integratio Mediação e Sustentabilidade que teve como parceira, em Sergipe, a Rosa dos Ventos Consultoria e Pesquisa, a fim de elaborarem os estudos que envolveu pesquisa para contextualização histórica, social, econômica e ambiental nos quais estão inseridas as tototós, plano de salvaguarda e delimitação da abrangência geográfica do ofício de canoeiro. 2 Instituto do Patrimônio Histórico e Artístico Nacional.

3 Embora o ofício de canoeiro vinculado às tototós encontra-se ameaçado desde 1948, portanto, 67 anos, essas embarcações cumprem sua função de transporte de passageiros pela foz do Rio Sergipe.

4 Software livre Quantum GIS, que se configura como um Sistema de Informações Geográficas - SIG.
} 


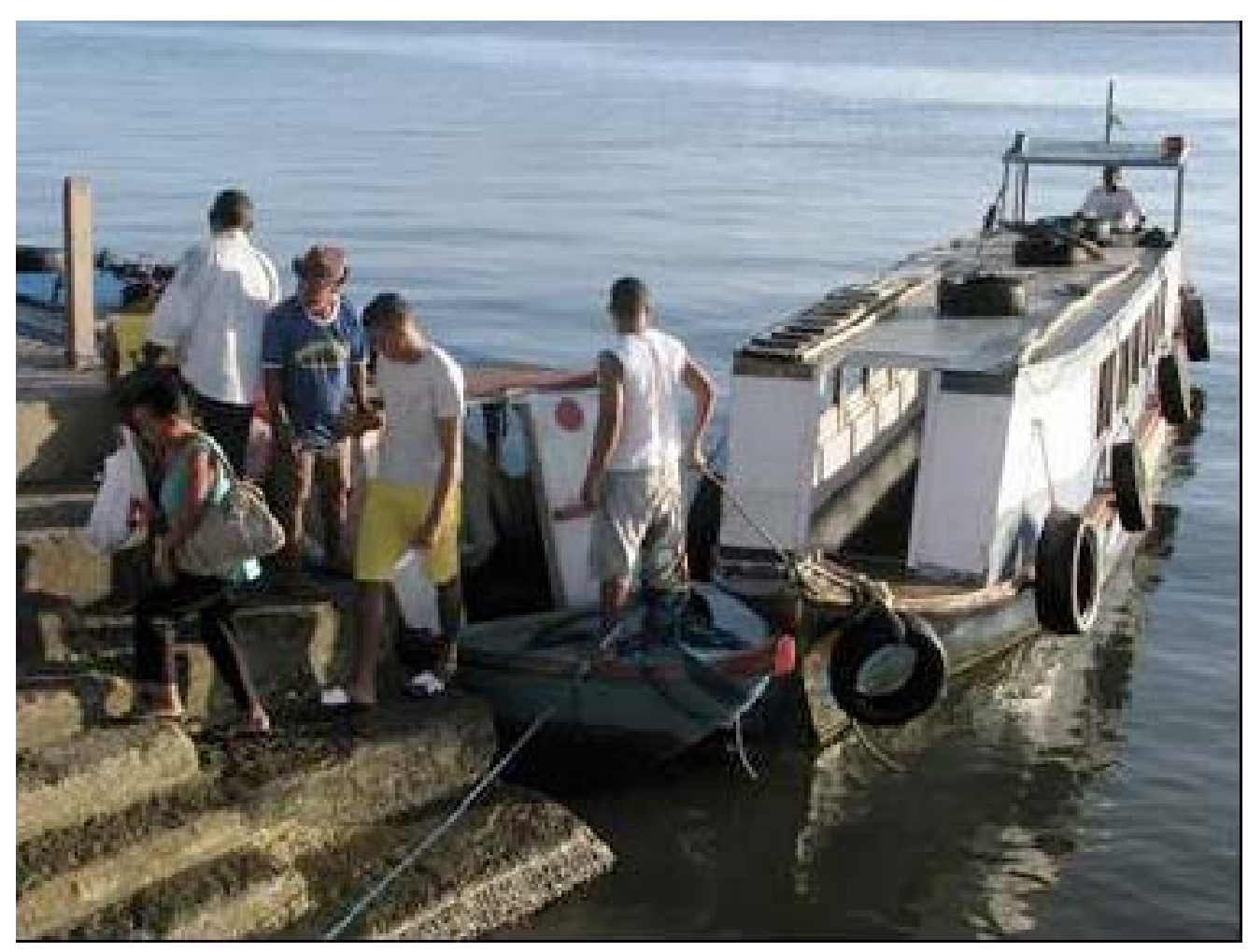

Figura 1 - Barqueiros das Tototós no transporte de passageiros Fonte: Acervo Iphan/SE

A proposta do presente artigo é integrar os agentes sociais e seus equipamentos para desenvolver compartilhamento e levar benefício para a comunidade com uma economia solidária, tendo como pontapé inicial o transporte de visitantes e turistas pelas tototós. Sendo as embarcações tototós patrimônio cultural estadual desde 2011, na primeira parte do artigo foi elaborada uma discussão contextualizando o que atualmente se entende por patrimônio naval brasileiro. A segunda parte discutiu o turismo de base local e o ofício de canoeiro e, por fim, a sugestão de roteiros turísticos para os canoeiros gerirem.

\section{Patrimônio cultural naval brasileiro}

A Constituição Brasileira de $1988^{5}$ espraiou a noção de patrimônio brasileiro partindo do aspecto histórico relacionado à ideia de passado para o cultural em que pese as manifestações do presente, vivas e pulsantes. Nesse contexto, buscou-se, a partir daí, fomentar a cultura do País por meio de leis de incentivo, marcando uma nova concepção em termos de salvaguarda dos bens materiais e imateriais vinculados aos mestres de ofício, detentores do saber e de técnicas.

\footnotetext{
5 “A Constituição Federal de 1988, em seus artigos 215 e 216, ampliou a noção de patrimônio cultural ao reconhecer a existência de bens culturais de natureza material e imaterial e, também, ao estabelecer outras formas de preservação - como o Registro e 0 Inventário - além do Tombamento, instituído pelo Decreto-Lei no. 25, de 30/11/1937, que é adequado, principalmente, à proteção de edificações, paisagens e conjuntos históricos urbanos. Os Bens Culturais de Natureza Imaterial dizem respeito àquelas práticas e domínios da vida social que se manifestam em saberes, ofícios e modos de fazer; celebrações; formas de expressão cênicas, plásticas, musicais ou lúdicas; e nos lugares (como mercados, feiras e santuários que abrigam práticas culturais coletivas)". Fonte: 〈http://portal.iphan.gov.br〉.
} 
Segundo Pereira (2008), é a partir dessa Constituição que a noção de cultura aparece homologada à noção de patrimônio. Nessa quebra de paradigma, dando uma nova percepção sobre o patrimônio brasileiro, verifica-se uma amplitude no que se refere ao conjunto de "saberes e fazeres" que torna a cultura brasileira singular. Ao longo das décadas de 1990 e 2000, viu-se o processo para perceber o patrimônio cultural como elemento vinculado à paisagem e lugar, e imbricado aos aspectos da memória, afetividade, costume e sustentabilidade ambiental, social e humana. Para Corrêa e Vargas (2011, p. 3), o patrimônio cultural deve ser,

[...] uma tendência que se projeta ao tema da memória, bastante em voga atualmente. A afirmação de identidades
histórico-culturais faz-se primordial na "era da globalização" sendo o fortalecimento e a salvaguarda dos bens cul-
turais considerados pilares do desenvolvimento humano e indicadores de sustentabilidade.

Durante a década de 90 do século passado, se viu por todo o País as primeiras ações para a valorização do patrimônio cultural para além da pedra e do cal. Nessa progressão, desde o início do século XXI, a cultura popular, artes e ofícios, advindos das populações tradicionais, passaram a ser vistos como elemento identitário e exaltados como patrimônio cultural brasileiro.

O longo processo de reconhecimento da produção material e imaterial originada do povo sempre foi esbarrado pelas dimensões territoriais do País, por políticas públicas que privilegiavam o patrimônio arquitetônico relacionado aos períodos Colonial e Imperial brasileiro e, por fim, na busca de uma cultura que, embora com uma identidade própria, estava vinculada ao erudito contrapondo e negando a produção cultural advinda do povo.

Em mais de um século, o discurso e as políticas públicas para salvaguarda da cultura popular passaram por mudanças na visão de órgãos de preservação e instituições de apoio à cultura e memória brasileira. Corroborando com esse pensamento, Funari e Pelegrini (2006) informam que nos últimos anos do século XX caiu por terra a noção considerada reducionista de patrimônio histórico, passando por novas centralidades e ampliando o conceito para patrimônio cultural.

Essa nova percepção para além da arte dos monumentos e grandes feitos artísticos, agora perpassa por memórias coletivas, ofícios e saberes que conferem identidade ao País. Ainda de acordo com os autores anteriormente citados (2006, p. 36), “[...] na década de 1980 foi consolidada entre os especialistas uma acepção ampliada do conceito de patrimônio, compreendido não só por produções de artistas ou intelectuais reconhecidos, mas estendido a criações anônimas, oriundas da alma popular". Nesse contexto, a salvaguarda dos bens culturais já é considerada como um dos pilares do desenvolvimento humano, sendo, pois, indicadora de educação, sustentabilidade e reconhecimento de si e do grupo (BRASIL, 2005).

Da ampliação do conceito de patrimônio, o Iphan coordenou os estudos que resultaram na edição do Decreto n. 3.551, de 04/08/2000 - que instituiu o Registro de Bens Culturais de Natureza Imaterial e criou o Programa Nacional do Patrimônio Imaterial (PNPI) - e consolidou o Inventário Nacional de Referências Culturais (INCR). Segundo o Iphan, o PNPI,

[...] viabiliza projetos de identificação, reconhecimento, salvaguarda e promoção da dimensão imaterial do patrimônio cultural. É um programa de apoio e fomento que busca estabelecer parcerias com instituições dos governos federal, estaduais e municipais, universidades, organizações não governamentais, agências de desenvolvimento e organizações privadas ligadas à cultura e à pesquisa. ${ }^{6}$

6 Disponível em: 〈http://portal.iphan.gov.br/〉. Acesso em: 21 jan. 2014. 
Por patrimônio cultural de natureza imaterial entende-se "os saberes, os ofícios, as festas, os rituais, as expressões artísticas e lúdicas que, integrados à vida dos diferentes grupos sociais, configuram-se como referências identitárias na visão dos próprios grupos que as praticam" (CASTRO; FONSECA, 2008, p. 12). Pode-se evocar aqui o entendimento da Unesco sobre patrimônio imaterial para entender que além de mutável, é relevante que ele esteja conectado com o meio ambiente, visto que esse tipo de patrimônio que:

[...] se transmite de geração em geração, é constantemente recriado pelas comunidades e grupos em função de seu ambiente, de sua interação com a natureza e de sua história, gerando um sentimento de identidade e continuidade e contribuindo assim, para promover o respeito à diversidade cultural e à criatividade humana (IPHAN, 2003 apud BRANCO, 2006, p. 2).

Em 2008, o Iphan lançou o projeto Barcos do Brasil cujo objetivo central se pautava na preservação e valorização do patrimônio naval brasileiro por meio de ações de proteção e diagnóstico de embarcações, paisagens culturais e acervos históricos, e fomento às atividades relacionadas com os barcos tradicionais - pesca, culinária, artesanato, festejos, transporte de pessoas e mercadorias e outras manifestações. Essa nova percepção a respeito dos meios fluviais e marítimos denota a relevância vinculada à cultura, história e identidade (PERALTA, 2003).

É oportuno trazer a discussão do que seja paisagem cultural, visto que a lei que confere às tototós patrimônio cultural sergipano vai além das 23 embarcações em funcionamento. Diz respeito a todo o contexto que envolve as embarcações, como costumes, memórias coletivas, modo de sobrevivência e estilo de vida. No tripé cultura, memória e identidade, vislumbra-se perceber aspectos da paisagem cultural, exaltada como elemento do patrimônio de uma localidade e oficializada pela Portaria Iphan n. 127, de 30 de abril de 2009. Documento este que reconhece o contexto cultural de saberes tradicionais, possuidores de aspectos que rebatem no cotidiano de uma comunidade.

Entende-se por "Paisagem Cultural Brasileira uma porção peculiar do território nacional, representativa do processo de interação do homem com o meio natural, à qual a vida e a ciência humana imprimiram marcas ou atribuíram valores" (BRASIL, 2009, p. 35). A vida simples relacionada à cotidianidade dos fazeres local, influenciando os costumes singulares dos ambientes aquáticos tais como rio, lago, lagoa e mar, enaltecendo a produção dos bens tangíveis e intangíveis das comunidades.

Na busca pelos diversos saberes oriundos das comunidades autóctones, como as ribeirinhas, catadoras e pescadoras, a arte da construção de canoas e barcos perpassa a valorização da tecnologia de construção, estética e beleza cênica compondo o patrimônio cultural brasileiro vinculado à paisagem marítimo-fluvial. Nesse contexto, órgãos de preservação (Iphan), autarquias federais (Ibama) e organizações não governamentais (Instituto Chico Mendes), ministérios: Cultura, Turismo, Educação, Pesca e Aquicultura, Ciência e Tecnologia, Cidades, assim como secretarias estaduais, municipais e empresas privadas têm trabalhado em ações que visem à valorização e preservação dos saberes relativos ao transporte, pesca e lazer das embarcações dos ambientes aquíferos.

O processo de salvaguarda foi iniciado com a canoa de tolda Luzitânia em Brejo Grande (SE) e o Saveiro de Vela de Içar Sombra da Lua (BA), que já possuem Tombamento Federal (BRASIL, 2013). Outras embarcações encontram-se inventariadas e diagnosticadas nas regiões Nordeste e Sul do País, como o cúter em São Luís (MA); bote bastardo em Camocim (CE); saveiro de vela de içar em Maragogipe (BA); saveiro de vela de pena em Itaparica (BA); canoa da Praia Vermelha em Salvador (BA); canoa pernambucana em Itapissuma (PE); bote de São Cristóvão (SE); canoa do Rio Real em Indiaroba (SE); baleeira de Armação do Pântano do Sul (SC); canoa bordada em Florianópolis (SC) (BRASIL, 2008). 
Além disso, governos e prefeituras, por meio do Poder Legislativo, têm buscado a valorização e reconhecimento dos saberes, ofícios e técnicas locais, chancelando-os mediante leis e decretos. Os projetos pleiteados abarcam os bens móveis, festas, celebrações religiosas, culinária, naval, entre outros, se alinhando às políticas de preservação e salvaguarda da instância federal. Ao detectar no arcabouço de produção tangível e intangível, proteção dos bens culturais marítimos, fluviais e lacustres, põem-se em evidência os saberes da localidade e estes passam a ser entendidos como essenciais à diversidade cultural e reveladores da identidade local.

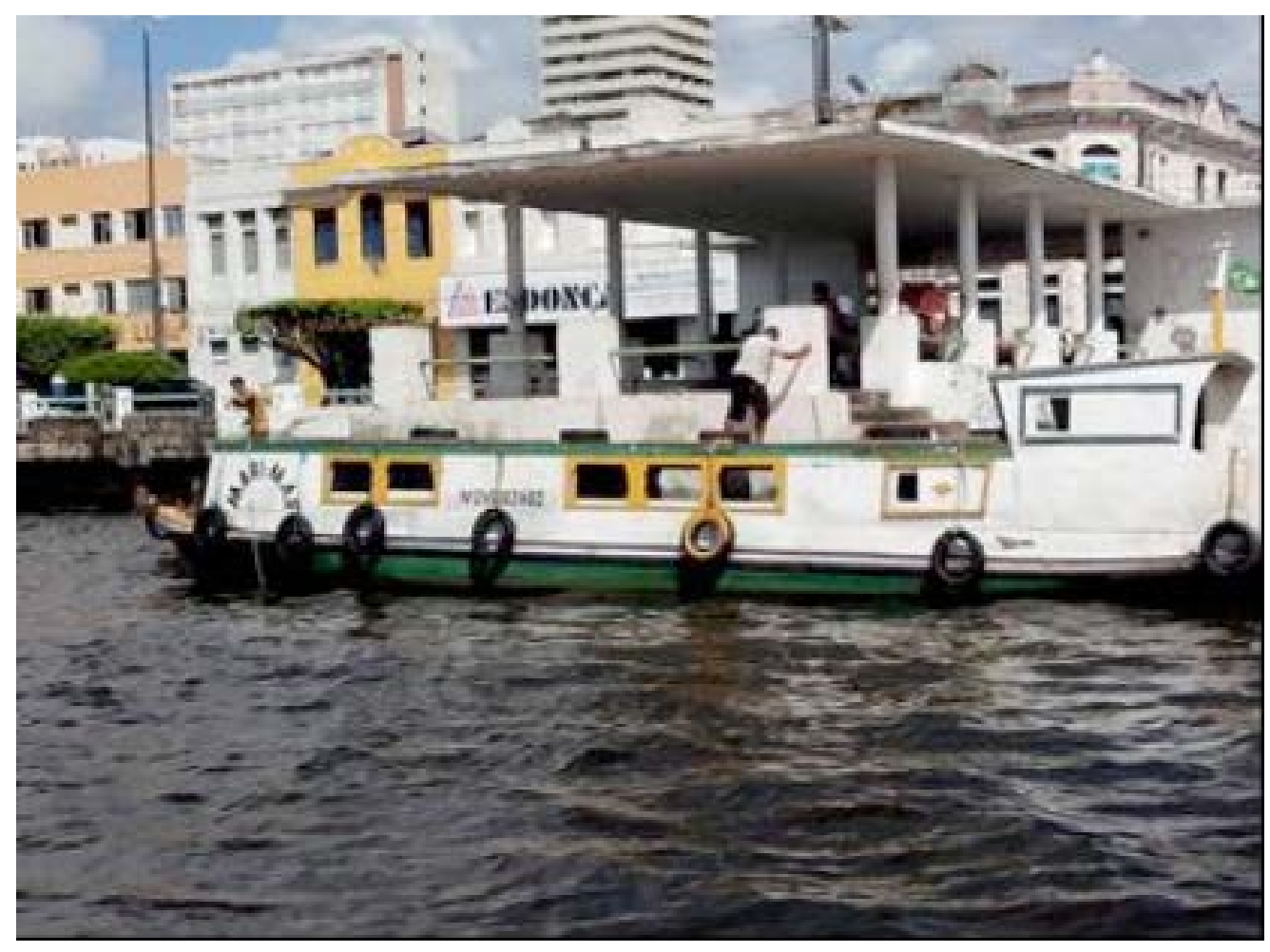

Figura 2 - Tototó do Rio Sergipe Fonte: Acervo Rosa dos Ventos Consultoria e Pesquisa

Em Sergipe, as embarcações de madeira movidas a motor e com ocorrência em alguns pontos fluviais de Sergipe denominadas tototós (Figuras 2 e 3) - desde a publicação no Diário Oficial da Lei n. 7.320, no dia 30 de dezembro de 2011, passaram a ser Patrimônio Cultural e Imemorial sergipano, de fato e de direito. No entanto, foi constatada que a relevância dessas embarcações não se encontra somente no objeto fluvial de transporte, mas em pessoas que trabalham nelas: condutores (proeiro e popeiro), carpinteiros náuticos (reformas e pequenos reparos), ou estão associadas: participantes de danças e folguedos (samba de coco), beneficiamento alimentar vegetal (catadoras de mangaba e coco) e atividades de coleta e catação animal (pescadores e marisqueiros). Daí a importância do Plano de Salvaguarda, bem como sugestão de roteiros turísticos para as tototós. 


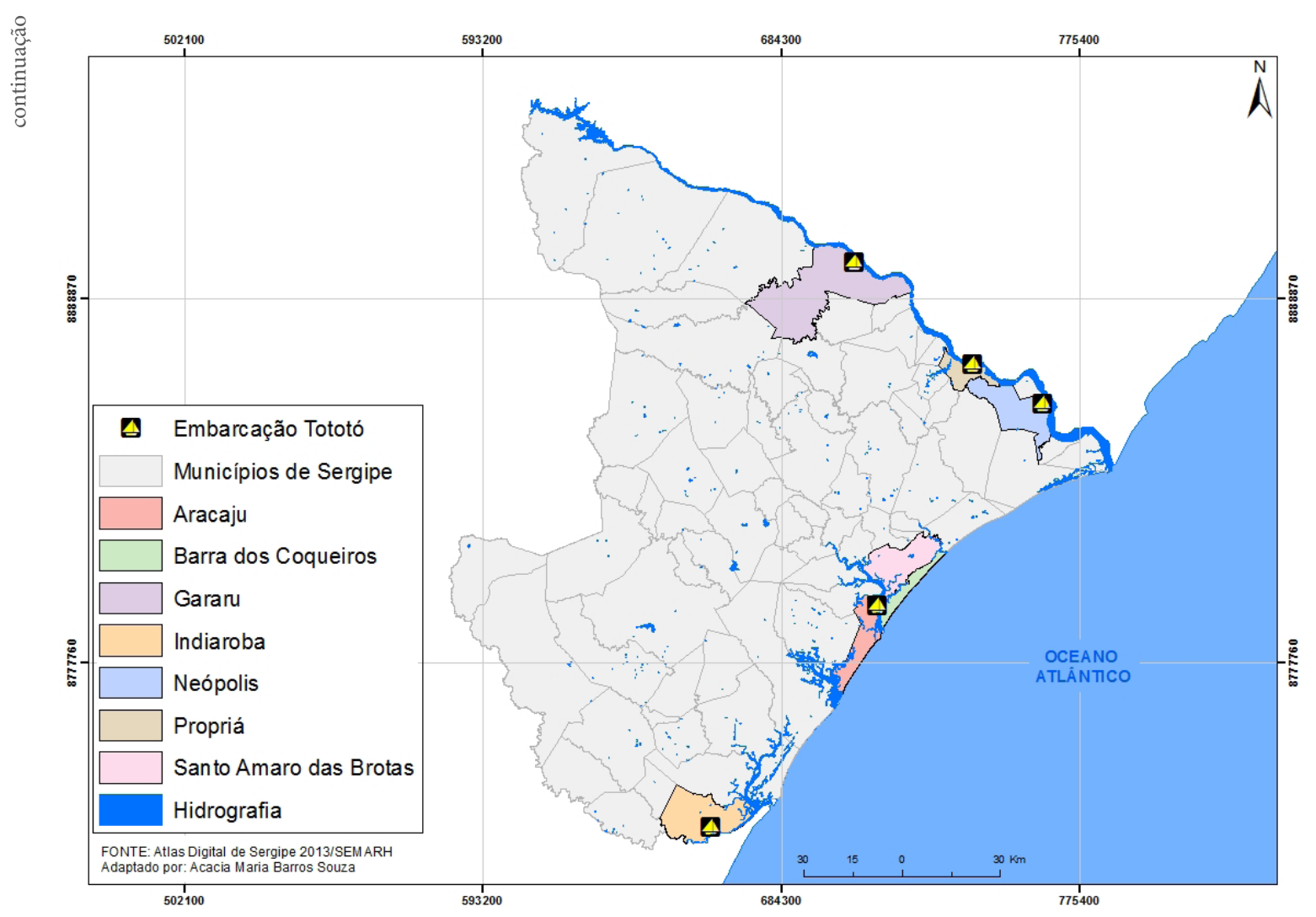

Figura 3 - Área de ocorrência das tototós no estado de Sergipe

Fonte: Acervo Rosa dos Ventos Consultoria e Pesquisa

\section{Turismo de base local e o ofício de canoeiro}

Em comunidades pesqueiras sejam marítimas ou fluviais, com grande potencial de belezas naturais, a iniciativa privada tem assumido papel de empreendedora da hotelaria e serviços turísticos. Tudo isso vem sendo realizado ao mesmo tempo em que deixa à margem o envolvimento da comunidade de pescadores com as suas reservas extrativistas e meio ambiente cênico. Sem contar que grande parte dos autóctones tende a trabalhar em atividades incomuns à sua realidade, acarretando em perdas de fazeres tradicionais de subsistência que lhe são próprios. Muitas vezes, são produções passadas de pai para filho, em que as técnicas utilizadas fazem parte do cotidiano dos moradores.

Outro fator que merece destaque diz respeito à exploração de mão de obra pelo turismo, em que são oferecidos para a comunidade de pescadores, agricultores e marisqueiros empregos que necessitam de baixa qualificação, acarretando no pagamento de salários injustos. Geralmente os cargos de gerência, ou de maior escalão, são ocupados por profissionais de outras regiões, o que representa um ponto negativo. Esse fato pode estar ligado à motivação de muitos jovens que saem de suas comunidades em direção aos grandes centros urbanos à procura de melhores condições de vida.

Nesse contexto, uma alternativa para a comunidade que desenvolve a atividade de transporte de passageiros (Figura 4) seria a adesão a roteiros turísticos em dias que as embarcações denominadas tototós 
ficam paradas. Tendo atualmente 20 barcos em ativa no Rio Sergipe $\mathrm{e}^{7}$ e pouca demanda para a travessia de pessoas entre margens, os canoeiros trabalham em regime de dias alternados, dando possibilidade de agendarem passeios turísticos pela região do estuário do Rio Sergipe nos dias em que as embarcações estariam paradas.

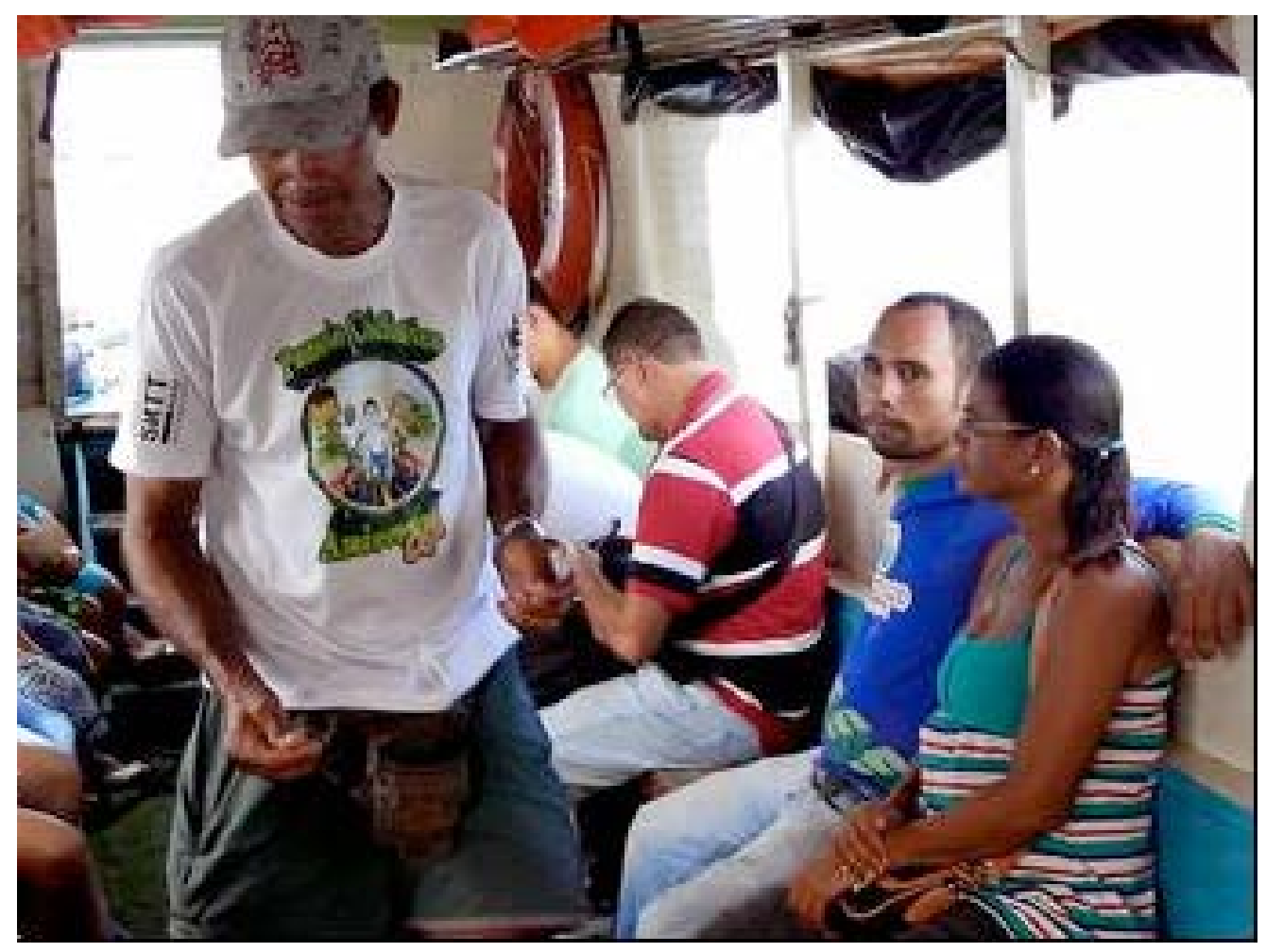

\section{Figura 4 - Transporte de Passageiros: principal atividade das tototós Fonte: Acervo Iphan/SE}

Essa proposta incluiria os barqueiros na cadeia produtiva do Turismo de Base Comunitária (TBC), visando estimular ações de protagonismo dos moradores. Como informam Burgos e Mertens (2015, p. 83) ao citarem Irving (2000), Bartholo, Sansolo e Bursztyn (2009) e Coriolano (2009b),

A exclusão das comunidades dos benefícios turísticos e o interesse na minimização dos efeitos nocivos da atividade sobre as populações locais estimularam uma nova forma de desenvolvimento do turismo que coloca a população local no centro do planejamento e promove práticas mais justas e sustentáveis.

Quer seja promovendo as especificidades culturais do lugar (gastronomia, festa, danças e artesanato), quer incentivando atividades vinculadas ao meio ambiente, extrativista e de pesqueira. Com o TBC, busca-se a permanência de todo o conjunto de bens patrimoniais próprios da localidade, procurando maneiras de mostrar como a natureza, a história, a tradição e a cultura local, além de apreciadas pelas suas belezas por visitantes, podem ser vetores de trabalho e comercialização para ganhos financeiros dos residentes. De acordo com Coriolano (2003, p. 282),

7 As outras três encontram-se: em reforma, sem condutor e um dos canoeiros não tem mais interesse em manter-se na atividade. 
[...] o turismo comunitário é aquele em que as comunidades de forma associativa organizam arranjos produtivos locais, possuindo o controle efetivo das terras e das atividades econômicas associadas à exploração do turismo. Nele o turista é levado a interagir com o lugar e com as famílias residentes, seja de pescadores, ribeirinhos, pantaneiros ou de índios.

$\mathrm{Na}$ foz do Rio Sergipe, para além da atividade turística de sol e praia, há alternativa do Turismo de Base Comunitária, possibilitando o enaltecimento das belezas naturais ligadas aos ecossistemas onde se localiza a comunidade barracoquierense. Além disso, se canoeiros gerirem os roteiros de passeios turísticos, ensinarão aos visitantes valorizar a cultura, a produção material, a identidade local e os ofícios, sejam de canoeiro, marisqueiro, catador de frutas da restinga.

Esse tipo de segmento turístico, aliado às práticas do turismo educativo, científico, cultural e o ecoturismo, oferece subsídios para a própria população do lugar, cria alternativas com o intuito de se tornar independente de subempregos, empregos públicos e de assistencialismo social vindos em posição verticalizada, de cima para baixo, e, quase sempre, não dando espaço para o desenvolvimento pessoal.

Ao implantar os roteiros sugeridos e se organizando de forma interna para a criação de uma Cooperativa de Turismo de Base Comunitária na Barra dos Coqueiros, os moradores (canoeiros, pescadores, marisqueiros, brincantes, catadores, artesãos e agricultores), promoverão as principais atividades econômicas originais da comunidade. Dessa maneira, estabelecerão uma base de modelo de desenvolvimento territorial endógeno como enfatiza Ramiro (2009), onde os elementos necessários para o desenvolvimento local estariam na própria comunidade, beneficiando os moradores.

Seriam atividades vinculadas aos fazeres da própria população com potencial de atrativo que, dependendo da intencionalidade e do arranjo produtivo, seriam vistas como produções que estão vinculadas à identidade local. Atividades que não devem ser substituídas pelo funcionalismo dos equipamentos de hotéis, bares, restaurantes e pousadas, mas estes incorporados aos moradores em localidade e ao seu modo de vida. De acordo com Ramiro (2009, p. 39), Arranjo Produtivo Local,

[...] são formas de organização da produção em um território em que se priorizam as vocações e recursos locais, o adensamento do mercado interno como forma de desenvolvimento sustentado e menos vulnerável às dinâmicas exteriores, sem ignorar a importância dos canais externos de comercialização [...].

Em Barra dos Coqueiros essas formas de organização poderiam ser fomentadas tanto pela Associação dos Proprietários de Canoas de Transporte de Passageiros e Fretes de Barra dos Coqueiros/SE (APCBC), pelas "Catadoras de Mangaba", grupos de folguedos populares e de extração animal - pescadores, catadores e marisqueiros (Figuras 5, 6, 7 e 8).

A discussão a respeito do Turismo de Base Comunitária perpassa os novos olhares de pesquisadores das ciências sociais (antropólogos, turismólogos e sociólogos) e das geociências, que têm debatido dentro e fora da academia os papéis a serem desempenhados por moradores e pelo trade turístico. Inclusive incluindo as comunidades locais, ouvindo-as e detectando, a partir das suas falas, as reais necessidades. Nesse contexto, escutar as comunidades para desenvolver o turismo demanda perceber seus anseios e dificuldades e propor projetos para uma articulação e valorização do seu espaço de origem.

\footnotetext{
8 Catadoras de Mangaba, Gerando Renda e Tecendo Vida é um projeto associativista em que mulheres utilizam a fruta da mangabeira para o beneficiamento alimentar. 0 município de Barra dos Coqueiros faz parte desse projeto. Fonte: 〈http://www.catadorasdemangaba.com.br/s.
} 

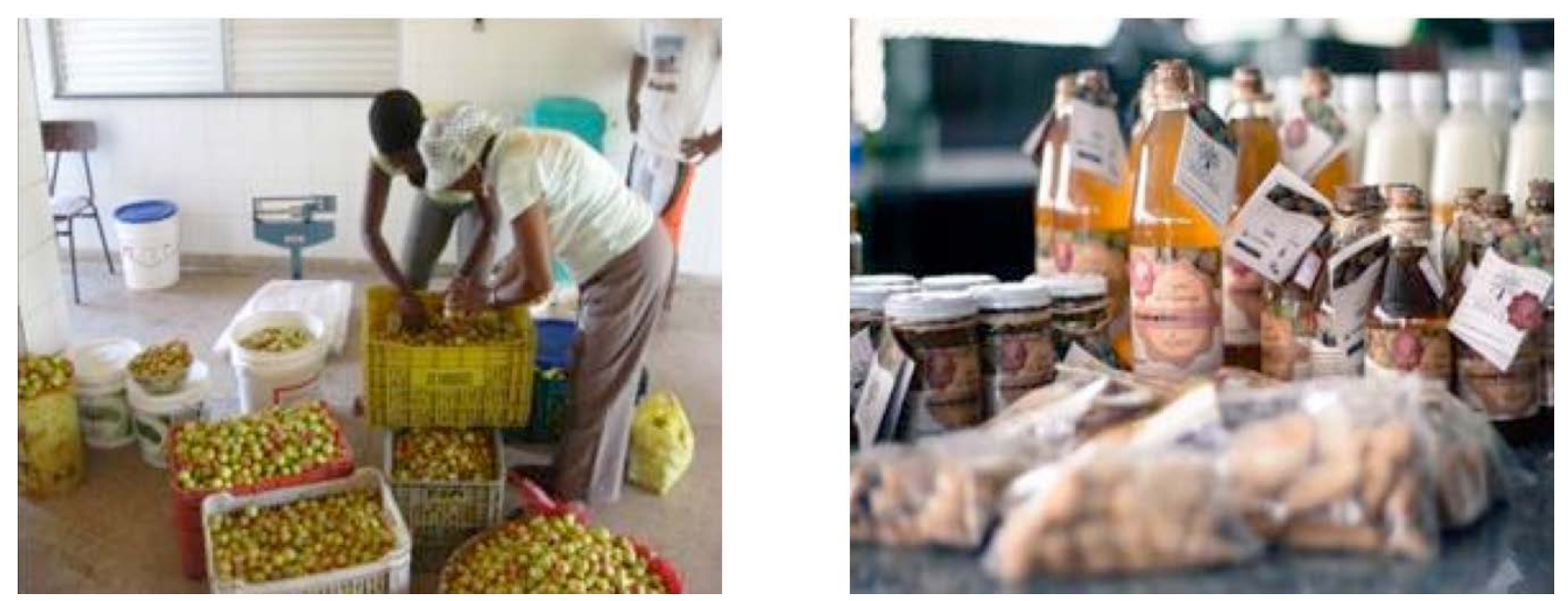

Figuras 5 e 6 - "Catadoras de Mangaba" e seus produtos

Fonte: http://www.infonet.com.br/

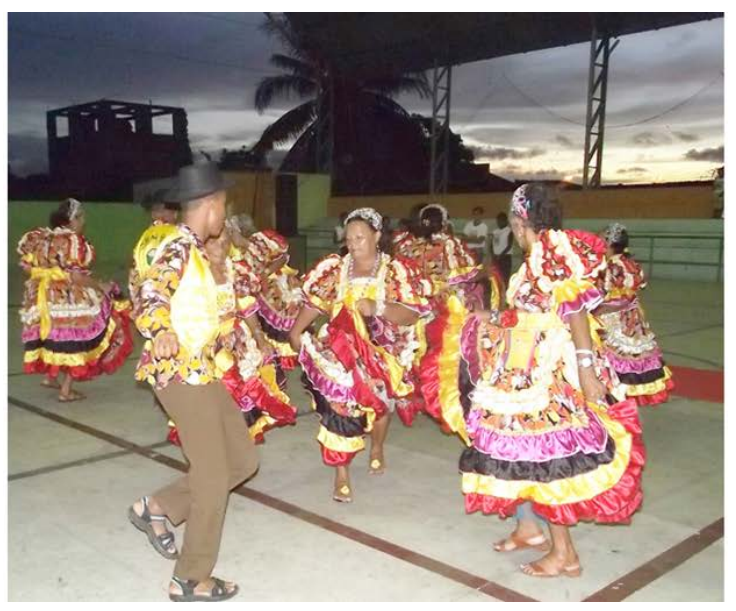

Figura 7 - Samba de Coco

Fonte: http://sambacocoegravura.blogspot.com.br/

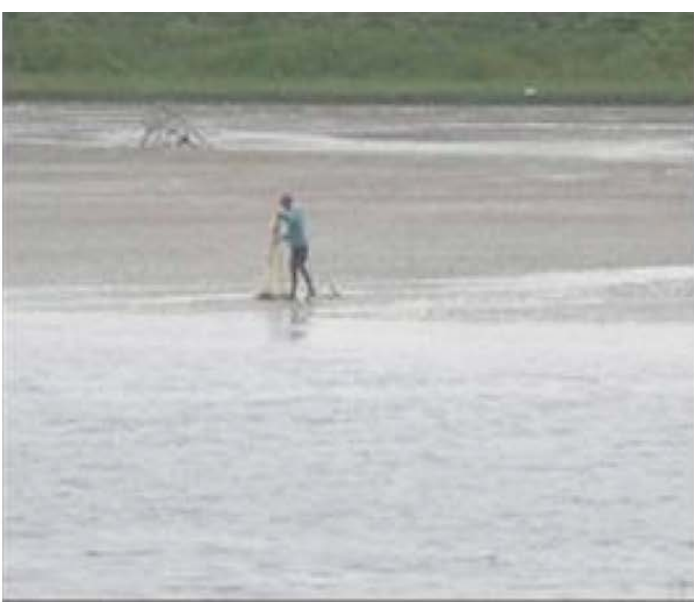

Figura 8 - Pescador

Foto: Ivan Rêgo Aragão, 2014

Cabe inserir reflexão sobre a alma do lugar, defendida por Yázigi (2001), que afirma estar no patrimônio ambiental com ar de cidade interiorana, o maior atrativo turístico local a ser preservado. O Turismo de Base Comunitária tem pensado na atividade turística como promotora dos saberes e fazeres locais, firmados na cultura popular, no ofício e na singularidade dos residentes, bem como a paisagem natural local, valorizando o meio ambiente e a cultura das pessoas inseridas na região com intuito de amenizar e/ ou erradicar a pobreza e a miséria local.

Desse modo, implantar o Turismo de Base Comunitária revelaria novos meios de desenvolver o lugar por meio da divulgação, circulação e venda dos atrativos e seus produtos específicos. Segundo Morgado (2006) apud Mendonça (2009, p. 291), como resultado, o Turismo de Base Local,

[...] é capaz de modificar a forma pela qual se dá a apropriação dos benefícios gerados pela atividade turística, pois diante dessa perspectiva, a comunidade se torna participante ativa de seu próprio desenvolvimento, e não apenas espectadora das atividades organizadas externamente, em que os benefícios financeiros não são percebidos localmente. 
Todavia, são necessários esforços que visem ao envolvimento da comunidade, visto que sua participação na gestão dos recursos naturais e econômicos de seu município é fundamental para que o turismo corresponda às expectativas dos moradores. Nesse enfoque, Coriolano (2009) destaca que os residentes devem ter o controle produtivo da atividade desde o planejamento até o desenvolvimento e gestão, se preocupando com o envolvimento participativo e com os resultados a serem obtidos. Segundo Brasil (2010, p. 8), o Turismo de Base Comunitária,

[...] é uma oportunidade para as populações locais possuírem o controle efetivo sobre o seu desenvolvimento, sendo diretamente responsáveis pelo planejamento e gestão das atividades, das estruturas e dos serviços turísticos propostos. [...] dialogando com os princípios que orientam e fortalecem relações solidárias entre homens e mulheres construtores/as de uma sociedade comprometida com a sustentabilidade em seus aspectos políticos, socioculturais, ambientais e econômicos.

A disponibilidade e utilização das tototós para outros fins, que não apenas o de travessia Aracaju - Barra dos Coqueiros, pode ser entendida como um modo, não o único, certamente, de valorizar e promover a continuidade sustentável desse bem. Para que possa se consolidar como uma ação prática, uma série de desafios precisará ser superada, como os previamente elencados neste texto. Acreditamos, contudo, que importantes passos já vêm sendo dados nessa direção. O ofício de canoeiro e os demais bens culturais a ele relacionado, vinculados à educação e ao turismo, representaria um avanço, e encontraria alinhamento com outros projetos de modelo de gestão do turismo realizados no Brasil, tais como, Acolhida na Colônia/ SC, Memorial do Homem Kariri/CE, Ecoturismo Comunitário em Mamiramá/AM, Turismo e Conservação em Silves/AM, Turismo e Resistência na Zona Costeira Cearense/CE, Projeto de roteiro do barro à Arte no Vale do Jequitinhonha/MG, entre outros.

A associação entre o turismo e os modos de vida tradicionais tem sido observada em diversos projetos cujo interesse é fortalecer o turismo, de modo a produzir maiores efeitos positivos para a comunidade local. Esse modelo de gestão do turismo, conhecido como TBC vem se constituindo como uma tendência mundial de ressignificação de espaços isolados, e/ou excluídos, com protagonismo de gestão das próprias comunidades. Segundo o Ministério do Turismo (BRASIL, 2010, p. 16), trata-se de "um modelo em que a cultura e os modos de vida locais são a principal motivação da visita, onde há o intercâmbio cultural entre o turista e a comunidade".

Na Barra dos Coqueiros, participantes de grupos folclóricos, canoeiros, catadoras de mangaba, pescadores, traduzem um modo de vida ainda pouco conhecido. Além dos costumes do meio de vida vinculado ao rio e bens culturais produzidos pela comunidade local, a beleza cênica da natureza fluvial também contribui para o desenvolvimento do turismo. O pôr do sol da praça da matriz e a vista de Aracaju, do outro lado do rio, também é um espetáculo para poucos. Relevante mencionar que não resta dúvida do potencial turístico-pedagógico de todos esses atrativos, e que esses mesmos canoeiros se interessassem pelo que foi aqui apresentado. Se isso acontecer, acredita-se que a mesma força que os impulsiona a seguir por tantos anos no ofício os levará a encantar visitantes locais e turistas de todo o mundo.

Conforme se observa, a proposta de ações dos quatro roteiros foi pensada de modo a contemplar e valorizar o lazer, os modos de fazer, as formas de expressão, os lugares, edificações e as celebrações associadas à prática e ao ofício dos canoeiros. 


\section{Proposta de ação e sugestão de roteiros turísticos para serem gerenciados pelos totozeiros}

A proposta de ação para implantação de roteiros turísticos está pautada em algumas etapas projetadas. Marcar reuniões em datas específicas com os agentes sociais de Barra dos Coqueiros para poder sugerir tais roteiros e escutá-los, visto que os moradores locais, detentores das tototós, pousadas, restaurantes e associações de beneficiamento alimentar e do artesanato, são quem vão gerenciar tais roteiros. As pessoas interessadas precisam estar cientes desses percursos que integrarão diversos atores sociais da comunidade, anotar sugestões, onde nada será imposto, mas uma construção coletiva.

A partir dessas ações, elaborar uma matriz SWOT $^{9}$ para poder planejar melhor o desenvolvimento da cadeia produtiva do turismo na região. Na pesquisa de campo e na escuta de alguns barqueiros já foram detectadas algumas fragilidades e potencialidades, porém, devem ser ouvidos os donos dos equipamentos de hospedagem, restauração e beneficiamento alimentar e produtores de artesanatos. Entre as fragilidades encontram-se: a falta de segurança apresentada pelas canoas, de mão de obra e qualificação profissional; a falta de infraestrutura dos atracadouros e a consequente dificuldade de acesso às canoas, sentida especialmente por idosos, pessoas com mobilidade reduzida e cadeirantes; a separação entre o ofício de canoeiro e o ofício do carpinteiro náutico, responsável pelas reformas e reparos nas canoas.

No que diz respeito às potencialidades, destacam-se: a possibilidade de valorização e utilização das canoas como meio de transporte no atendimento a outros roteiros além do que já é realizado entre Aracaju e Barra dos Coqueiros; elaboração e execução de passeios pedagógicos e turísticos. Como a rica fauna e flora que caracterizam o mangue, o estuário do Rio Sergipe contempla ainda a possibilidade de interpretação patrimonial em função do acervo edificado do centro antigo de Aracaju.

Seja pelo viés pedagógico onde segundo Matos (2012) o turismo possui uma relação direta com o ensino-aprendizagem, pois as atividades lúdico-pedagógicas realizadas fora da sala de aula se vinculam aos conteúdos programáticos disciplinares, cumprindo de forma lúdica e dinâmica os objetivos do processo pedagógico; seja por meio da base local, a nova percepção da atividade turística já constata que a associação entre o turismo e os modos de vida tradicionais tem sido observada em diversos projetos cujo interesse tem sido fortalecer o turismo de modo a produzir maiores efeitos positivos para a comunidade local.

A seguir, os quatro roteiros como sugestão para desenvolver o TBC em Barra dos Coqueiros tendo os canoeiros como os agentes protagonistas da atividade.

\section{Foz do Rio Sergipe: história, cultura e meio ambiente}

Este passeio teria como foco proporcionar uma abordagem histórica das cidades de Aracaju e Barra dos Coqueiros por meio da interpretação do conjunto patrimonial de edificações presentes na Avenida Ivo do Prado. ${ }^{10}$

\footnotetext{
9 Também conhecida como matriz FOFA esse tipo de metodologia constata forças e fraquezas, oportunidades e ameaças. 10 Avenida de Aracaju que margeia o Rio Sergipe.
} 
Como ponto de partida, sairia pela manhã do Atracadouro das Tototós, ${ }^{11} \mathrm{em}$ frente do Mercado Municipal. Nesse caso, as pessoas seriam levadas a um passeio pela foz do Rio Sergipe em direção ao encontro das águas do rio com o Oceano Atlântico. Todos os roteiros deverão contar com a participação de guias ou canoeiros credenciados. O roteiro incluiria o repasse de informações que contemplasse as construções com relevância histórico-cultural como o antigo prédio da alfândega, o espaço cultural Zé Peixe (antigo terminal hidroviário), a Praça Fausto Cardoso, o Museu Palácio Olímpio Campos, a Ponte do Imperador, o Museu da Gente Sergipana, o prédio do antigo colégio Atheneuzinho, o Centro de Cultura e Arte Cultart (antigo prédio da Escola de Direito), a casa onde morou Zé Peixe, o Edifício Atalaia (primeiro prédio residencial de altitude em Aracaju), a sede da OAB (antigo casarão dos Rollemberg), o Iate Clube de Aracaju, a orla da Praia Formosa, o Mirante da 13 de Julho e a Ponte Godofredo Diniz (que dá acesso ao Shopping RioMar).

De volta no sentido do atracadouro, o roteiro contemplaria a outra margem do rio para visualização da riqueza natural da fauna e flora do mangue, destacando a importância de sua preservação e dando ênfase à vegetação e fauna endêmicas. Durante essa parte do trajeto, seria comentada sobre a possibilidade de visualização do Boto-cinza, espécie presente no rio. Em Barra dos Coqueiros, seria realizada uma parada para conhecer a oficina do carpinteiro náutico e a praça onde se encontra a Igreja de Santa Luzia. No roteiro denominado "Foz do Rio Sergipe: História, Cultura e Meio Ambiente", alguns equipamentos de restauração alimentar dariam suporte ao roteiro: Restaurante Caçarola, Restaurante de Zé Américo (sanfoneiro de Campo do Brito), Restaurante Xaxado, Restaurante do Museu da Gente Sergipana.

\section{Ilha da Tartaruga com APA Morro do Urubu}

Nesta segunda opção de roteiro, as pessoas partiriam, pela manhã, de um dos atracadouros (Aracaju ou Barra dos Coqueiros) e seriam levadas em um passeio de tototó pelo Rio Sergipe e Rio Pomonga, chegando à Ilha da Tartaruga, onde permaneceriam para tomar banho no rio e almoçar no Restaurante Preta e Preto. À tarde, de volta a Aracaju, um micro-ônibus levaria as pessoas para visitarem o Parque da Cidade - APA do Morro do Urubu, podendo assistir ao pôr do sol do ponto mais alto do morro, alcançado com a utilização do teleférico.

\section{Culturas, fazeres \& sabores da Barra dos Coqueiros}

O roteiro "Culturas, Fazeres \& Sabores da Barra dos Coqueiros" (Figura 9), seria realizado de modo a contemplar a península da Barra dos Coqueiros. Pela manhã, através de um passeio de tototó pelas margens do rio, poderia ser dada ênfase à vegetação endêmica, aves nativas, à importância de preservação dos manguezais, bem como à relevância histórica e econômica que a Barra dos Coqueiros representou, principalmente nas décadas de 1940 a 1970 do século XX. Após almoço em um dos restaurantes locais, os visitantes seriam levados a conhecer o projeto "Catadoras de Mangaba, Gerando Renda e Tecendo Vida”, onde assistiriam, ao final da tarde, a uma apresentação do Samba de Coco ou Reisado.

11 Poderia ser realizada uma parceria com receptivos de turismo locais e os visitantes poderiam ser recolhidos nos equipamentos de hospedagem mais importantes da capital, como o Hotel Águas Marinhas, Pousada do Frade, Hotel Real Classic, Sandrin Praia Hotel, Hotel Litoral, Simas Praia Hotel, Pousada São Luiz, entre outros. 


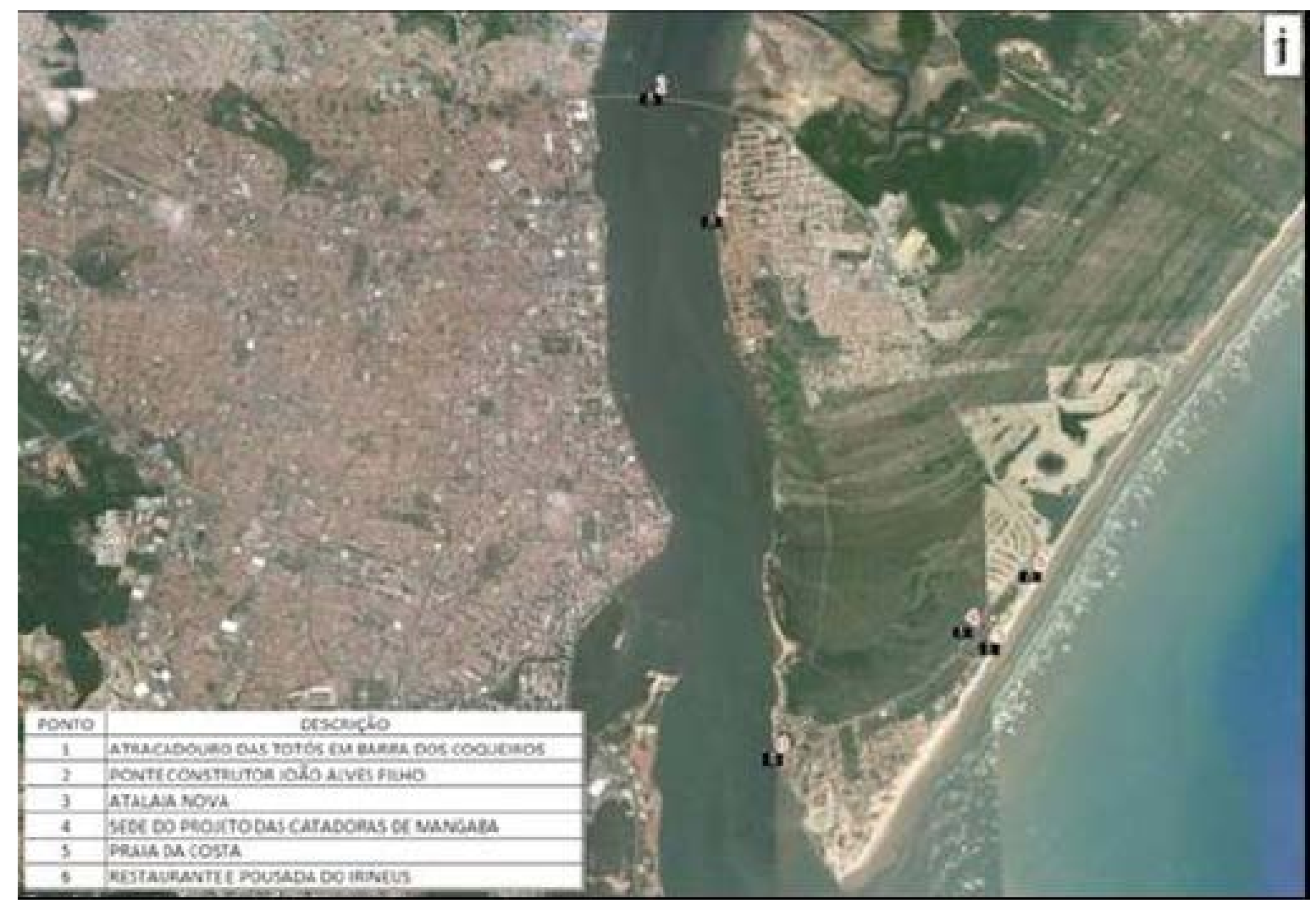

\section{Figura 9- Imagem de Satélite com os pontos do Roteiro Turístico "Culturas, Fazeres \& Sabores da Barra dos Coqueiros"}

Fonte: Google Satélite através da ferramenta Open Layers Plugin do QGIS, adaptado por Rosa dos Ventos Consultoria e Pesquisa (2014)

\section{Aracaju / Itha da Tartaruga com pernoite em Barra dos Coqueiros ou Santo Amaro das Brotas}

Esta opção de roteiro (Figura 10) pressuporia a utilização dos equipamentos hoteleiros existentes na Barra dos Coqueiros, como o Prodigy Beach Resort \& Conventions Aracaju, a Pousada Cristina e a Pousada e Restaurante Irineu's ou ainda a Fazenda Barreirinhas, localizada no município de Santo Amaro das Brotas. Partindo do atracadouro de Barra dos Coqueiros pela manhã, as pessoas seriam levadas a um passeio pelo Rio Sergipe. À tarde, após almoço em um dos restaurantes da orlinha do bairro industrial, os turistas seriam levados à Ilha da Tartaruga.

A depender do interesse e do número de turistas, o passeio ofereceria pernoite na Barra dos Coqueiros ou na Fazenda Barreirinhas. Os passeios que optarem pela hospedagem na fazenda, podem oferecer o segundo dia de descanso e lazer na própria fazenda, que conta com piscina, área de recreação com churrasqueira e píer. Já os passeios cujo pernoite se realizar na Barra dos Coqueiros, poderiam oferecer a manhã do segundo dia na praia da Costa ou uma visita à sede das Catadoras de Mangaba e, à tarde, uma visita ao Parque Eólico. 


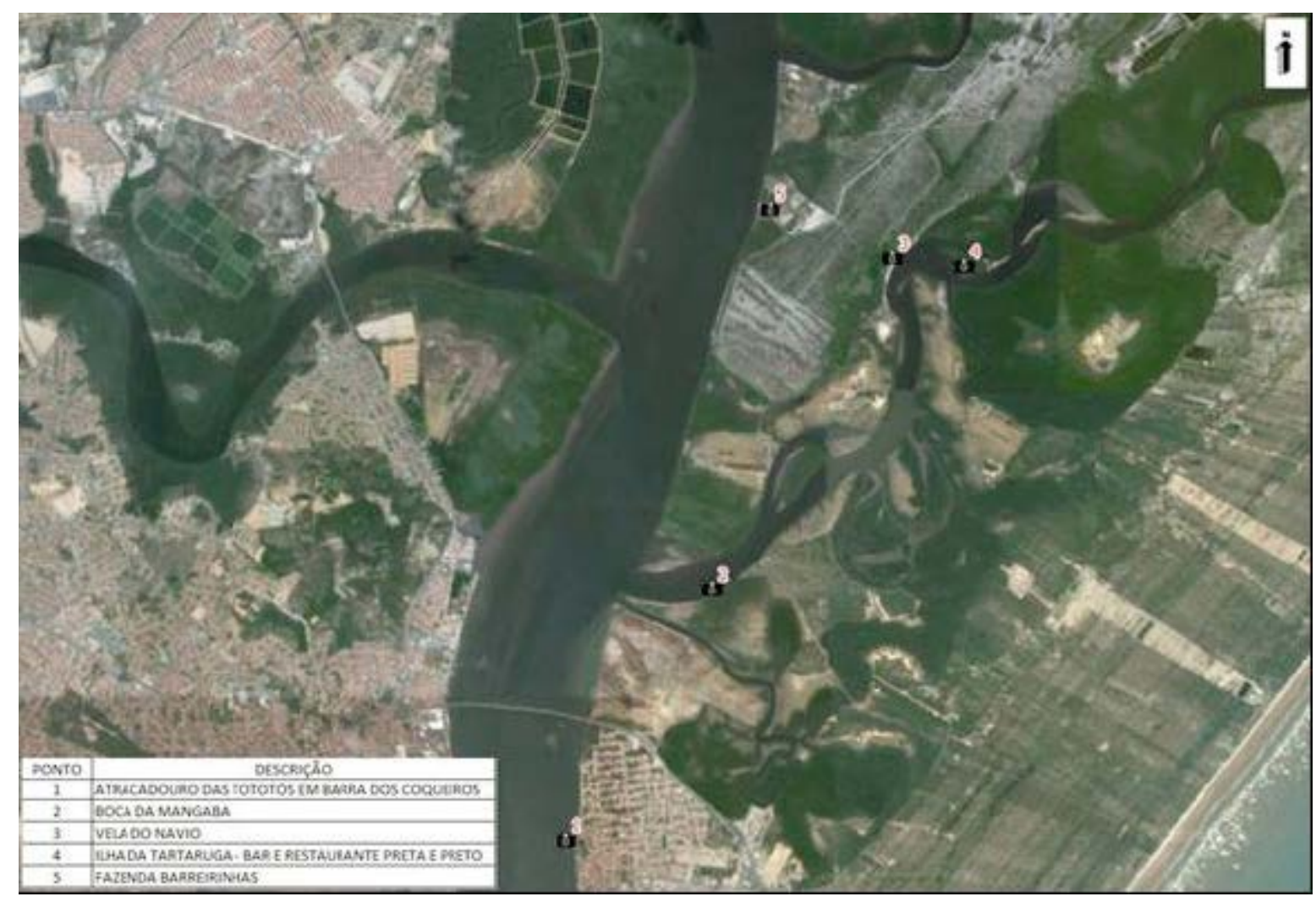

\section{Figura 10 - Imagem de Satélite de pontos do Roteiro Turístico "Aracaju / Ilha da Tartaruga com pernoite em Barra dos Coqueiros ou Santo Amaro das Brotas"}

Fonte: Google Satélite através da ferramenta Open Layers Plugin do QGIS, adaptado por Acácia Souza/Rosa dos Ventos Consultoria e Pesquisa (2014)

Conforme se observa, as ações dos roteiros foram pensadas de modo a contemplar e valorizar os ofícios e modos de lazer, as formas de expressão, os lugares e edificações, bem como as celebrações associadas à prática e ao ofício dos canoeiros. A disponibilidade na utilização das tototós no transporte de passageiros em outros roteiros, não apenas o da travessia Aracaju / Barra dos Coqueiros pode ser entendida como um modo, não o único, certamente, de valorizar e promover a continuidade sustentável do bem.

\section{CONSIDERAÇÕES FINAIS}

Além do ofício de canoeiro das tototós vinculado ao transporte de passageiros, a proposta que se expôs no presente artigo foi buscar soluções para, por meio de novos usos, sentidos e significados, possibilitar uma maior visibilidade e valorização da categoria, tendo os bens culturais e patrimoniais associados a esse modo de fazer.

Com o aporte do inventário nacional de referências culturais (INRC) que, por meio de uma visão antropológica, busca inventariar, identificar para poder entender o contexto em que se inserem comu- 
nidades guardiãs dos bens patrimoniais - tanto ambientais como culturais - foram sugeridos roteiros turísticos alinhados ao segmento do TBC.

Nesse sentido, a proposta de roteiros propõe incentivos para o protagonismo da comunidade local por meio da utilização de produções materiais e cenários geográficos diferenciados, buscando qualificar a mão de obra para gerir a atividade e desenvolver uma economia solidária. Buscou-se, portanto, no âmbito do estuário do Rio Sergipe, sugerir roteiros turísticos para o protagonismo dos canoeiros das embarcações tototós.

\section{REFERÊNCIAS}

AMAZONAS. Pousada Uacari. Ecoturismo de base comunitária na reserva de desenvolvimento sustentável Mamiramá. Projeto Bagagem Brasil, 2010. Rede Turisol.

. Pousada aldeia dos lagos. Uma experiência de turismo e conservação em Silves. Projeto Bagagem Brasil, 2010. Rede Turisol.

BARTHOLO, R; SANSOLO, D. G; BURSZTYN, I. (Org.). Turismo de base comunitária: diversidades de olhares e experiências brasileiras. Rio de Janeiro: UFRJ, Letra e Imagem, 2009.

BRANCO, P. M. C. Patrimônio: um diálogo entre história e turismo. In: Anais do XVIII Encontro Regional de História. ANPUH/SP - Unesp/Assis, 24 a 28 de julho de 2006. p. 1-10. CD-ROM.

BRASIL. Inventário Nacional de Referências Culturais - INRC. Brasília: Iphan, 2000.

. Década da Educação das Nações Unidas para um Desenvolvimento Sustentável, 2005-2014: documento final do esquema internacional de implementação. Brasília: Unesco, 2005

. Projeto Barcos do Brasil. Iphan, 2008.

. Paisagem cultural. Iphan, 2009.

. Dinâmica e diversidade do turismo de base comunitária: desafio para a formulação de política pública. Brasília: Ministério do Turismo, [s. ed.], 2010.

BURGOS, A; MERTENS, F. A perspectiva relacional na gestão do turismo de base comunitária: o caso da Prainha do Canto Verde. In: Caderno Virtual de Turismo. Rio de Janeiro, v. 15 n. 1., p. 81-98, abr. 2015.

CASTRO, M. L. V. de; FONSECA, M. C. L. Patrimônio imaterial no Brasil. Brasília: Unesco, Educarte, 2008.

CEARÁ. Memorial do homem Kariri. Turismo de conteúdo no sertão do Cariri. Fundação Casa Grande, 2010. Rede Turisol.

רา . Turismo e resistência na zona costeira cearense. Projeto Bagagem Brasil, 2010. Rede Turisol e Tucum.

CORIOLANO, L. N. T. O desenvolvimento voltado às condições humanas e ao turismo comunitário. In: CORIOLANO, L. N. T; LIMA, L. C. Turismo comunitário e responsabilidade socioambiental. Fortaleza: Eduece, 2003. p. 26-44. 
. O turismo comunitário no nordeste brasileiro. In: BARTHOLO, R; SANSOLO, D. G; BURSZTYN, I. (Org.). Turismo de base comunitária: diversidades de olhares e experiências brasileiras. Rio de Janeiro: UFRJ, Letra e Imagem, 2009. p. 277-288.

Arranjos Produtivos Locais do Turismo Comunitário: atores e cenários em mudanças. Fortaleza: UECE, 2009b.

CORRÊA, I. C. C.; VARGAS, M. A. A. Memória e identidade: traços da festa de Bom Jesus dos Navegantes no bairro Atalaia - Aracaju/SE. In: XI Congresso Luso Afro Brasileiro de Ciências Sociais, Salvador, UFBA, 07 a 10 de agosto de 2011.

FUNARI, P. P.; PELEGRINI, S. C. A. Patrimônio Histórico e Cultural. Rio de Janeiro: Jorge Zahar, 2006.

IRVING, M. de A. Ecoturismo em áreas protegidas: um desafio no contexto brasileiro. Boletim de Turismo e Administração Hoteleira, v. 9, n. 2, 2000.

MATOS, F. de C. Turismo Pedagógico: o estudo do meio como ferramenta fomentadora do currículo escolar. In: Anais do VII Seminário de Pesquisa em Turismo do Mercosul - SEMINTUR, Caxias do Sul, UCS, 16 e 17 de nov. de 2012. p. 1-11.

MENDONÇA, T. C. de M. Turismo socialmente responsável da Prainha do Canto Verde: uma solução em defesa do local herdado. In: BARTHOLO, R; SANSOLO, D. G; BURSZTYN, I. (Org.). Turismo de base comunitária: diversidades de olhares e experiências brasileiras. Rio de Janeiro: UFRJ, Letra e Imagem, 2009. p. 289-301.

PERALTA, E. O mar por tradição: o patrimônio e a construção das imagens do turismo. In: Horizontes Antropológicos, Porto Alegre, ano 9, n. 20, outubro de 2003, p. 83-96.

PEREIRA, J. C. O conceito de cultura na Constituição Federal de 1988. In: IV Encontro de Estudos Multidisciplinares em Cultura - ENECULT, Faculdade de Comunicação/UFBA, Salvador-Bahia-Brasil, 28 a 30 de maio de 2008. p. 1-12.

RAMIRO, R. Economia solidária e turismo. Brasília: IABS, AECID, MTur, 2009.

SANTA CATARINA. Turismo comunitário: agroturismo em Santa Catarina. Projeto Acolhida na Colônia, 2010. Rede Turisol.

YÁZIGI, E. A alma do lugar: turismo, planejamento e cotidiano em litorais e montanhas. São Paulo: Contexto. 2001. (Coleção Turismo) 